\title{
Simulation-Based Optimization of Aspect Ratio in Tungsten Inert Gas Welding
}

\section{Chukwuemeka Odoemelam, Joseph Ifeanyi Achebo, Jacob Odeh Ehiorobo, John Osadolor Osaremwinda}

Department of Production Engineering, University of Benin, Benin City, Nigeria

Email:chuodoems@gmail.com,josephachebo@yahoo.co.uk

How to cite this paper: Odoemelam, C., Achebo, J.I., Ehiorobo, J.O. and Osaremwinda, J.O. (2018) Simulation-Based Optimization of Aspect Ratio in Tungsten Inert Gas Welding. Engineering, 10, 876-890. https://doi.org/10.4236/eng.2018.1012061

Received: October 24, 2018

Accepted: December 25, 2018

Published: December 28, 2018

Copyright (c) 2018 by authors and Scientific Research Publishing Inc. This work is licensed under the Creative Commons Attribution International License (CC BY 4.0).

http://creativecommons.org/licenses/by/4.0/

\section{c) (i) Open Access}

\begin{abstract}
The shape of the fusion zone after weld in terms of its width-to-depth ratio is known as the aspect ratio, large aspect ratios in welded joints usually results in cracks formation during solidification of the weld; it also results in tensile residual stresses at the fusion zone. In this study, central composite design matrix was employed using Design Expert 7.01 software to optimize the aspect ratio of mild steel welded joint. A total of 20 sets of experiments were produced; the weld specimen was mild steel plate measuring $60 \mathrm{~mm} \times 40 \mathrm{~mm} \times$ $10 \mathrm{~mm}$. TIG welding machine with $100 \%$ Argon Shielding Gas was used for this experiment and at the end of the experiment, an optimum weld aspect ratio of 0.646 was achieved using current of $140 \mathrm{amp}$, voltage of 25 volt and gas flow rate of $15 \mathrm{~L} / \mathrm{min}$. This value of 0.646 is expected to contain the minimum adequate molten metal just enough to make the desired bead penetration to form good aspect ratio at a minimum cost with appropriate weld quality and productivity. This would help minimize the formation of cracks after weld.
\end{abstract}

\section{Keywords}

Welded Joints, Aspect Ratio, Mild Steel, TIG, Weld Crack

\section{Introduction}

Premature failure of welded structures had resulted in great loss of life and properties; it had also been a huge engineering problem, huge source of concern cutting across all strata of engineering [1] failures that often results from welded joint can sometimes be linked to poor combinations of process parameters which often manifest in the form of cracks [2]. Their work proved that some of these failures originate at welded joints; this area is very critical to the overall lifespan of the weld is determined by the welded joint. 
Visual defects appearance in welds compromises the quality of weldment and can manifest in forms such as deformation, excessive undercut, porosity, and cracks. Crack defects are regarded as the worst since even a minute crack can grow and lead to failure [3] that is why a good weld aspect ratio is required for quality welded joints. [4] showed that metal structures at their welded joints, do not have the same strength characteristics as the parent material; this means to optimize the strength enhancing properties at the welded joint; optimum process parameters are required. And to further minimize the cost of try and error approach, a robust design of experiment would be imperative [5].

It was suggested by [6] that one of the proven ways of enhancing the strength and lifespan of structural material at welded joints is to optimize its aspect ratio where, the optimum weld parameter is geared towards ensuring quality weld all the time. Over the years, the desired process parameters of welded joints have been gleamed out by applying various multi criteria optimization tools and statistical models in an attempt to broaden the scope, and increase the options open to researchers and developers in arriving at optimum process parameters to meet specific needs [7] and [8]. According to [9] and [10], the preferred welding parameters are selected based on knowledge or from a welding handbook. It should be noted that, this does not ensure that the selected welding parameters can make the best or near best weld bead profile for that particular welding process and environment. It is therefore desirous to produce welded joints and metal products that are of high quality, but with more precision, less energy, and time constraints by careful selection of the various process control parameters through some established guidelines or models.

\section{Materials and Methods}

\subsection{Materials}

One hundred (100) pieces of mild steel coupons, measuring $60 \mathrm{~mm} \times 40 \mathrm{~mm} \times$ $10 \mathrm{~mm}$ were used for the experiments, the experiment was performed 20 times using, 5 specimen for each run. Figure 1 shows the weld torch. Figure 2 shows

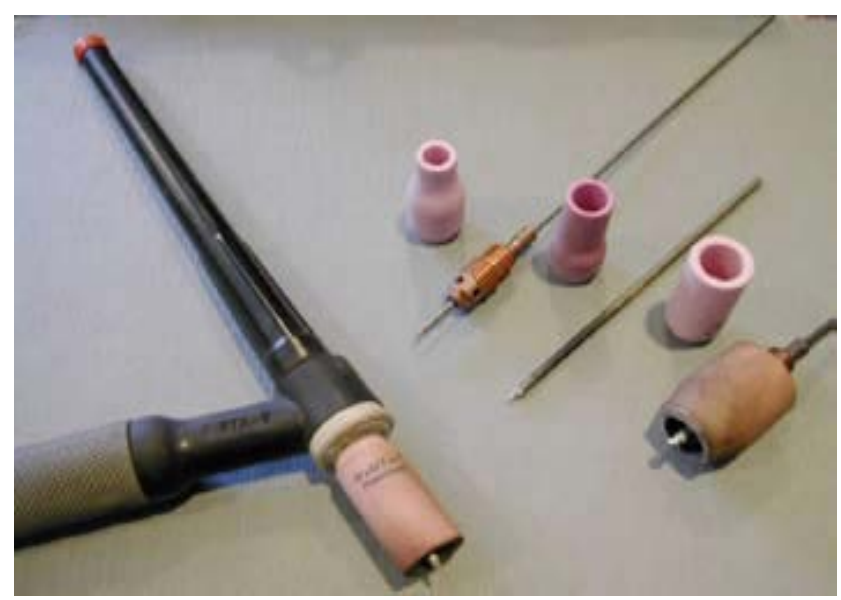

Figure 1. TIG welding torch. 


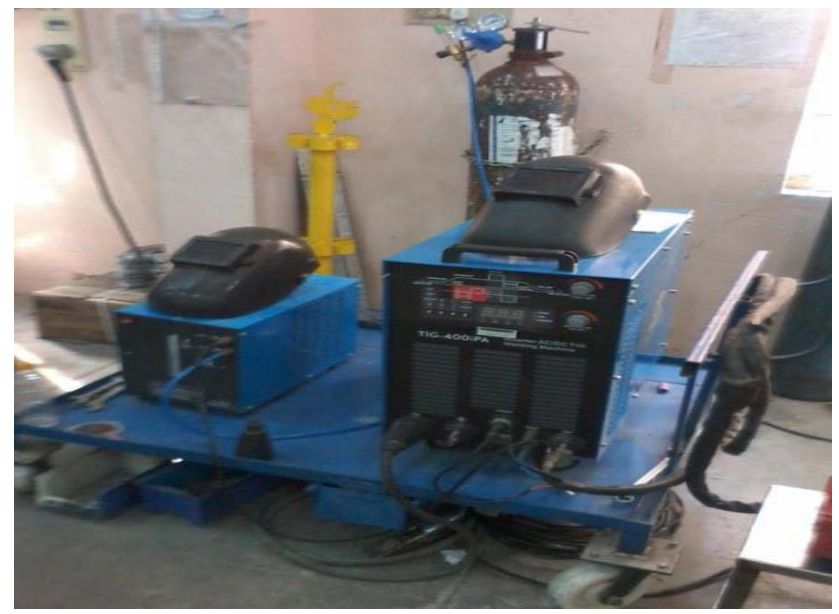

Figure 2. TIG equipment.

the TIG machine. Figure 3 shows the argon gas cylinder and regulator for varying the gas flow rate while. Figure 4 shows the mild steel weld sample. The range of values of the process parameters was obtained from the open literature accessed and each parameter has two levels which comprise the high and low as expressed in Table 1.

\subsection{Methods}

The Central Composite Design matrix with 6 central points, 6 axial points and 8 factorial points was developed using the Design Expert 7.01 software, which produced 20 experimental runs. The input parameters and output parameters made-up the experimental matrix and the responses recorded from the weld samples were used as the data. Figure 5 shows the Central Composite Design matrix.

\section{Results and Discussion}

\subsection{Results}

The optimization objective was to reduce the aspect ratio of welded joint, the randomized design matrix comprising of three input variables (current, voltage and gas flow rate) and their ranges in real values is presented in Figure 6, the response variable of interest is circled in orange colour.

The model summary which shows the factors and their lowest and highest values including the mean and standard deviation is presented as shown in Figure 7.

Result of Figure 7 revealed that the model is of the quadratic type which requires the polynomial analysis order as depicted by a typical response surface design. The minimum value of aspect ratio was observed to be 0.514 with a maximum value of 0.975 , mean value of 0.790 and standard deviation of 0.144 .

Analysis of the model standard error was employed to assess the suitability of response surface methodology using the quadratic model to minimize the aspect 


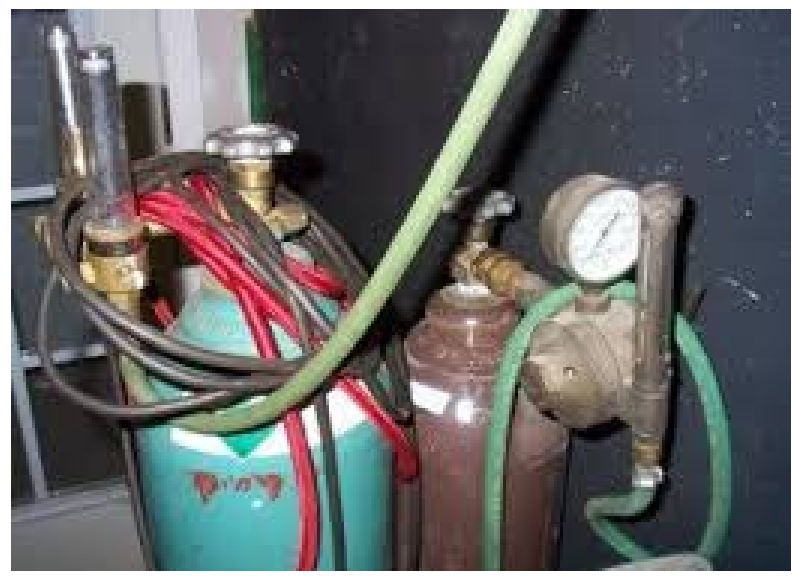

Figure 3. Shielding gas cylinder and regulator.

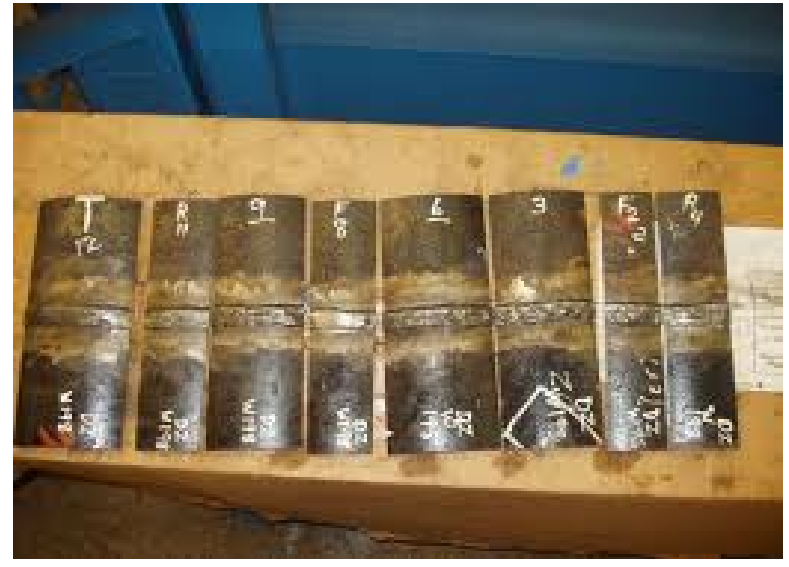

Figure 4. Weld samples.

\begin{tabular}{|c|c|c|c|c|c|}
\hline Std & Run & Type & $\begin{array}{l}\text { Factor } 1 \\
\text { A:Current } \\
\text { Amp }\end{array}$ & $\begin{array}{c}\text { Factor } 2 \\
\text { B:Voltage } \\
\text { volt }\end{array}$ & $\begin{array}{c}\text { Factor } 3 \\
\text { C:Gas Flow Rate } \\
\text { L/min }\end{array}$ \\
\hline 15 & 1 & Center & 155.00 & 23.50 & 13.50 \\
\hline 16 & 2 & Center & 155.00 & 23.50 & 13.50 \\
\hline 17 & 3 & Center & 155.00 & 23.50 & 13.50 \\
\hline 18 & 4 & Center & 155.00 & 23.50 & 13.50 \\
\hline 19 & 5 & Center & 155.00 & 23.50 & 13.50 \\
\hline 20 & 6 & Center & 155.00 & 23.50 & 13.50 \\
\hline 9 & 7 & Axial & 129.77 & 23.50 & 13.50 \\
\hline 10 & 8 & Axial & 180.23 & 23.50 & 13.50 \\
\hline 11 & 9 & Axial & 155.00 & 20.98 & 13.50 \\
\hline 12 & 10 & Axial & 155.00 & 26.02 & 13.50 \\
\hline 13 & 11 & Axial & 155.00 & 23.50 & 10.98 \\
\hline 14 & 12 & Axial & 155.00 & 23.50 & 16.02 \\
\hline 1 & 13 & Fact & 140.00 & 22.00 & 12.00 \\
\hline 2 & 14 & Fact & 170.00 & 22.00 & 12.00 \\
\hline 3 & 15 & Fact & 140.00 & 25.00 & 12.00 \\
\hline 4 & 16 & Fact & 170.00 & 25.00 & 12.00 \\
\hline 5 & 17 & Fact & 140.00 & 22.00 & 15.00 \\
\hline 6 & 18 & Fact & 170.00 & 22.00 & 15.00 \\
\hline 7 & 19 & Fact & 140.00 & 25.00 & 15.00 \\
\hline 8 & 20 & Fact & 170.00 & 25.00 & 15.00 \\
\hline
\end{tabular}

Figure 5. Central Composite Design Matrix (CCD). 


\begin{tabular}{|c|c|c|c|c|c|c|c|c|c|}
\hline Std & Run & Type & $\begin{array}{l}\text { Factor } 1 \\
\text { A:Current } \\
\text { Amp }\end{array}$ & $\begin{array}{l}\text { Factor } 2 \\
\text { B:Voltage } \\
\text { volt }\end{array}$ & $\begin{array}{c}\text { Factor } 3 \\
\text { C:Gas Flow Rate } \\
\text { L/min }\end{array}$ & $\begin{array}{l}\text { Response } 1 \\
\text { Aspect Ratio } \\
\text { Nil }\end{array}$ & $\begin{array}{c}\text { Response } 2 \\
\text { Volume of Weld Metal Deposit } \\
\mathrm{mm}^{\wedge} 3 / \mathrm{s}\end{array}$ & $\begin{array}{c}\text { Response } 3 \\
\text { Electrode Heat Transfer Coefficient } \\
\text { W/m² OC }\end{array}$ & $\begin{array}{c}\text { Response } 4 \\
\text { Rate of Heat Transfer } \\
\text { J/S }\end{array}$ \\
\hline 15 & 1 & Center & 155.00 & 23.50 & 13.50 & 0.9511 & 1255.38 & 259.78 & 3264 \\
\hline 16 & 2 & Center & 155.00 & 23.50 & 13.50 & 0.9513 & 1255.42 & 259.77 & 3266 \\
\hline 17 & 3 & Center & 155.00 & 23.50 & 13.50 & 0.9512 & 1255.39 & 259.79 & 3267 \\
\hline 18 & 4 & Center & 155.00 & 23.50 & 13.50 & 0.9511 & 1255.41 & 259.8 & 3265 \\
\hline 19 & 5 & Center & 155.00 & 23.50 & 13.50 & 0.9512 & 1255.38 & 259.78 & 3264 \\
\hline 20 & 6 & Center & 155.00 & 23.50 & 13.50 & 0.9513 & 1255.41 & 259.79 & 3266 \\
\hline 9 & 7 & Axial & 129.77 & 23.50 & 13.50 & 0.5136 & 1037.78 & 272.49 & 2992 \\
\hline 10 & 8 & Axial & 180.23 & 23.50 & 13.50 & 0.6842 & 1278.34 & 260.24 & 3400 \\
\hline 11 & 9 & Axial & 155.00 & 20.98 & 13.50 & 0.6256 & 1251.3 & 222.82 & 2805 \\
\hline 12 & 10 & Axial & 155.00 & 26.02 & 13.50 & 0.8312 & 1198.65 & 255.62 & 3128 \\
\hline 13 & 11 & Axial & 155.00 & 23.50 & 10.98 & 0.9752 & 1125.94 & 248.23 & 2932.5 \\
\hline 14 & 12 & Axial & 155.00 & 23.50 & 16.02 & 0.7704 & 1149.76 & 243.61 & 3187.5 \\
\hline 1 & 13 & Fact & 140.00 & 22.00 & 12.00 & 0.709 & 1061.3 & 243.61 & 2618 \\
\hline 2 & 14 & Fact & 170.00 & 22.00 & 12.00 & 0.8485 & 1200.99 & 266.71 & 3323.5 \\
\hline 3 & 15 & Fact & 140.00 & 25.00 & 12.00 & 0.8147 & 1020.26 & 239.91 & 2856 \\
\hline 4 & 16 & Fact & 170.00 & 25.00 & 12.00 & 0.7204 & 1317.83 & 248.23 & 3612.5 \\
\hline 5 & 17 & Fact & 140.00 & 22.00 & 15.00 & 0.602 & 1176.44 & 215.89 & 2967 \\
\hline 6 & 18 & Fact & 170.00 & 22.00 & 15.00 & 0.7633 & 1135.17 & 235.92 & 3012 \\
\hline 7 & 19 & Fact & 140.00 & 25.00 & 15.00 & 0.606 & 1116.7 & 289.87 & 2975 \\
\hline 8 & 20 & Fact & 170.00 & 25.00 & 15.00 & 0.6378 & 1234.9 & 273.61 & 3368 \\
\hline
\end{tabular}

Figure 6. Design matrix showing the real values and the experimental values.

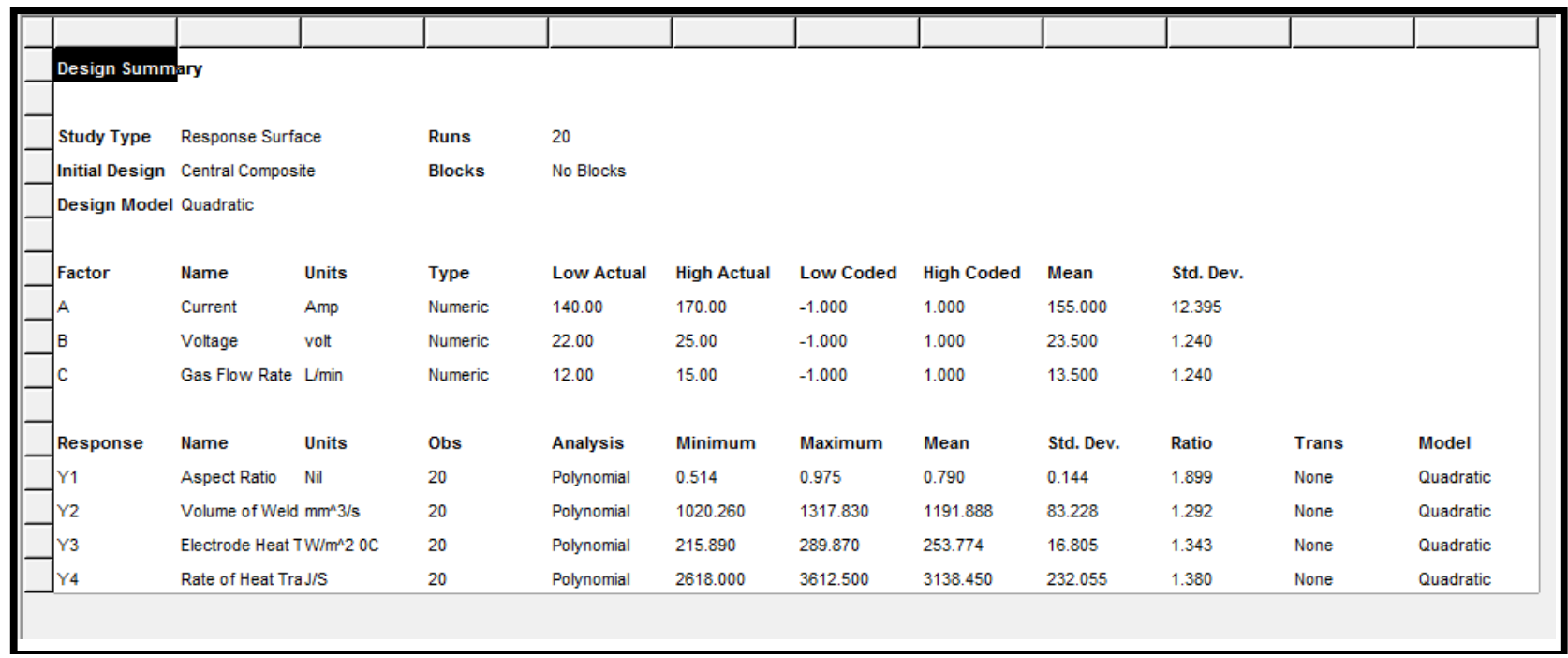

Figure 7. RSM design summary for optimizing weld parameters.

Table 1. Welding parameters and their levels.

\begin{tabular}{|c|c|c|c|c|}
\hline \multirow{2}{*}{ Parameters } & \multirow{2}{*}{ Unit } & \multirow{2}{*}{ Symbol } & \multicolumn{2}{|c|}{ Coded value } \\
\hline & & & Low $(-1)$ & High (+1) \\
\hline Current & Amp & A & 120 & 190 \\
\hline Gas flow rate & $\mathrm{Lit} / \mathrm{min}$ & G & 10 & 17 \\
\hline Voltage & Volt & $\mathrm{V}$ & 20 & 27 \\
\hline
\end{tabular}

ratio. The computed standard errors for the selected responses are presented in Figure 8.

From the results of Figure 8, it was observed that the model have a low standard 


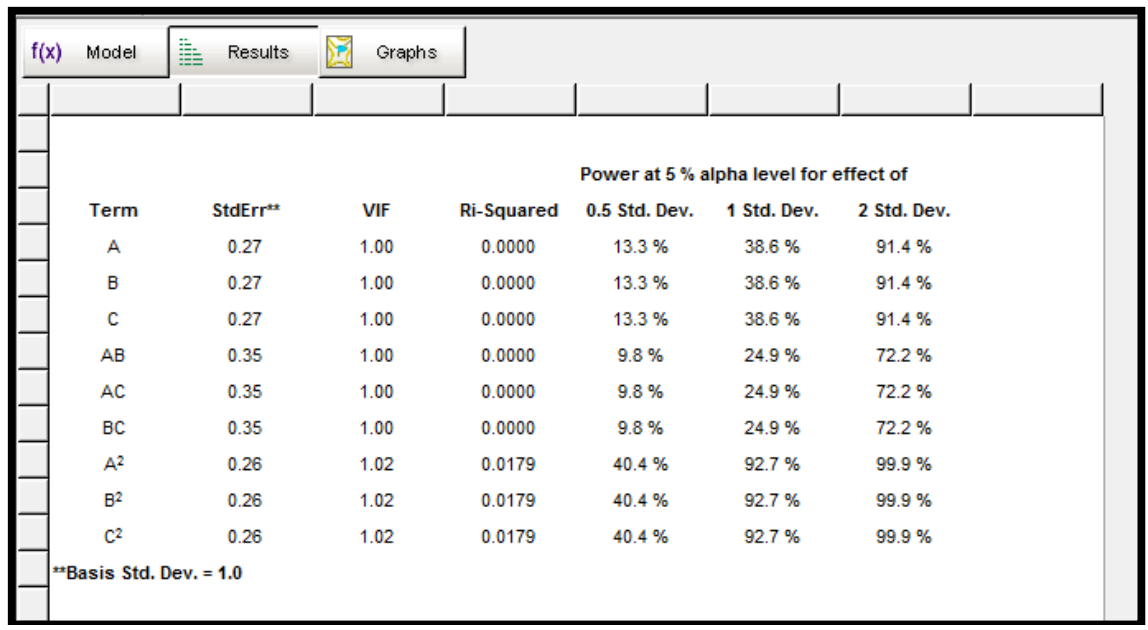

Figure 8. Result of computed standard errors.

error ranging from 0.27 for the individual terms, 0.35 for the combine effects and 0.26 for the quadratic terms. Standard errors should be similar within type of coefficient; smaller is better. The Variance inflation factor (VIF) of approximately 1.0 as observed in Figure 8 was good since ideal VIF is 1.0. In addition, the Ri-squared value was observed to be between 0.0000 to 0.0179 which is good. The correlation matrix of regression coefficient is presented in Figure 9. Lower values of the off diagonal matrix as observed in Figure 9 indicates a well fitted model that is strong enough to navigate the design space and adequately optimize the selected response variables.

Leverages of 0.6698 and 0.6073 calculated for the factorial and axial points coupled with 0.1663 for the center point as observed in Figure 10 shows that the predicted values are very close to the experimental values. Hence lower residual value which shows the adequacy of the model.

In assessing the strength of the quadratic model towards minimizing the aspect ratio, one way analysis of variance (ANOVA) was done for each response variable and result is presented in Figure 10 Analysis of variance was needed to check whether or not the model is significant and also to evaluate the significant contributions of each individual variable and their combined and quadratic effects towards each response.

From the result of Figure 10, the Model F-value of 18.34 implies the model is significant. There is only a $0.01 \%$ chance that a "Model F-Value" this large could occur due to noise. Values of "Prob > F" less than 0.0500 indicate model terms are significant. In this case A, C, AB, A2, B2, C2 are significant model terms. Values greater than 0.1000 indicate the model terms are not significant.

To validate the adequacy of the model based on its ability to minimize the aspect ratio, the goodness of fit statistics presented in Figure 11 were employed.

To obtain the optimal solution, we first consider the coefficient statistics and the corresponding standard errors. The computed standard error measures the difference between the experimental terms and the corresponding predicted 


\begin{tabular}{|c|c|c|c|c|c|c|c|}
\hline$f(x) \quad$ Model & Results & (7) Graphs & & & & & \\
\hline & & & & & & & \\
\hline \multicolumn{8}{|c|}{ Correlation Matrix of Regression Coefficients } \\
\hline & Intercept & A & $\mathrm{B}$ & c & $A B$ & $A C$ & $\mathrm{BC}$ \\
\hline Intercept & 1.000 & & & & & & \\
\hline A & -0.000 & 1.000 & & & & & \\
\hline B & -0.000 & -0.000 & 1.000 & & & & \\
\hline c & -0.000 & -0.000 & -0.000 & 1.000 & & & \\
\hline$A B$ & -0.000 & -0.000 & -0.000 & -0.000 & 1.000 & & \\
\hline $\mathrm{AC}$ & -0.000 & -0.000 & -0.000 & -0.000 & -0.000 & 1.000 & \\
\hline $\mathrm{BC}$ & -0.000 & -0.000 & -0.000 & -0.000 & -0.000 & -0.000 & 1.000 \\
\hline$A^{2}$ & -0.529 & -0.000 & -0.000 & -0.000 & -0.000 & -0.000 & -0.000 \\
\hline$B^{2}$ & -0.529 & -0.000 & -0.000 & -0.000 & -0.000 & -0.000 & -0.000 \\
\hline$c^{2}$ & -0.529 & -0.000 & -0.000 & -0.000 & -0.000 & -0.000 & -0.000 \\
\hline
\end{tabular}

Figure 9. Correlation matrix of regression coefficients.

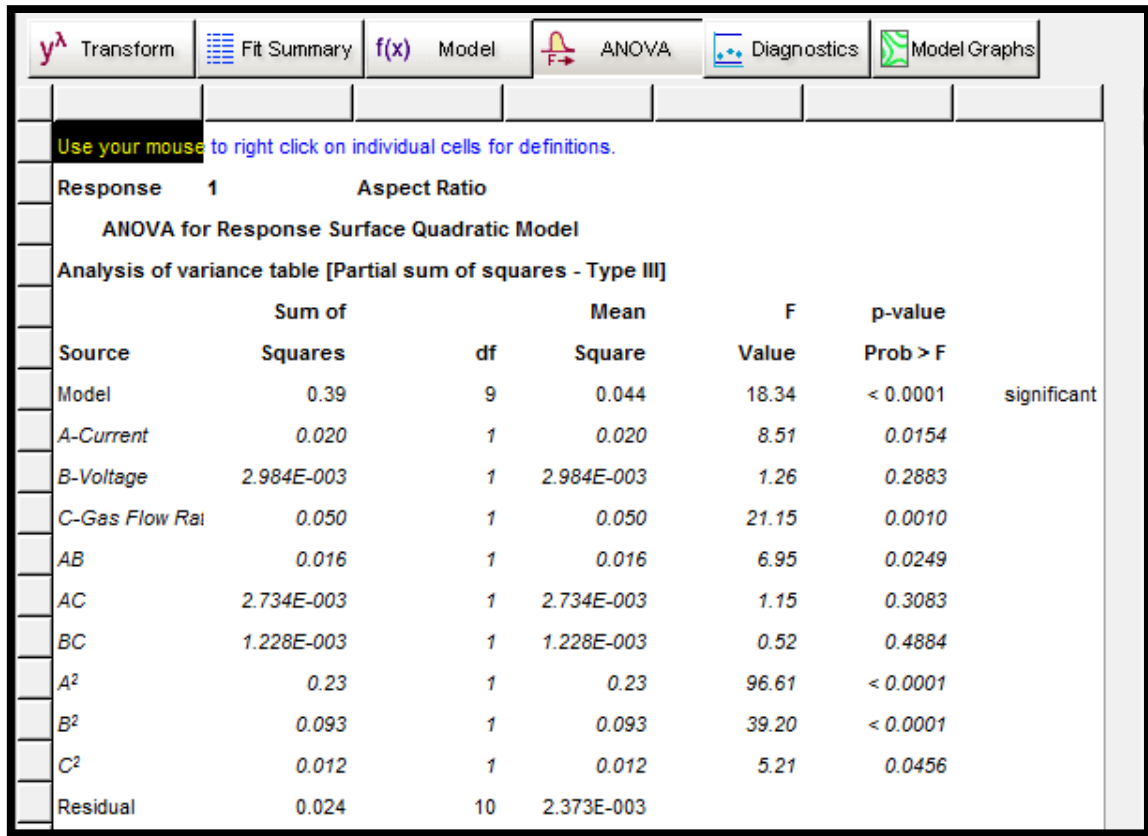

Figure 10. ANOVA table for validating the model significance towards minimizing the Aspect Ratio (AR).

\begin{tabular}{|c|c|c|c|c|c|}
\hline$y^{\lambda}$ Transform & 僬 Fit Sumnary & $f(x)$ Model & $\frac{\Omega}{F \rightarrow}$ ANOVA & & Model Graphs \\
\hline Std. Dev. & 0.049 & & R-Squared & 0.9429 & \\
\hline Mean & 0.79 & & Adj R-Squared & 0.8915 & \\
\hline C.V. $\%$ & 6.16 & & Pred R-Squared & 0.5609 & \\
\hline PRESS & 0.18 & & Adeq Precision & 12.790 & \\
\hline
\end{tabular}

Figure 11. GOF statistics for validating model significance towards minimizing the aspect ratio.

terms. Coefficient statistics for aspect ratio is presented in Figure 12.

Variance inflation factor (VIF) value of 1.00 for the individual and combine 


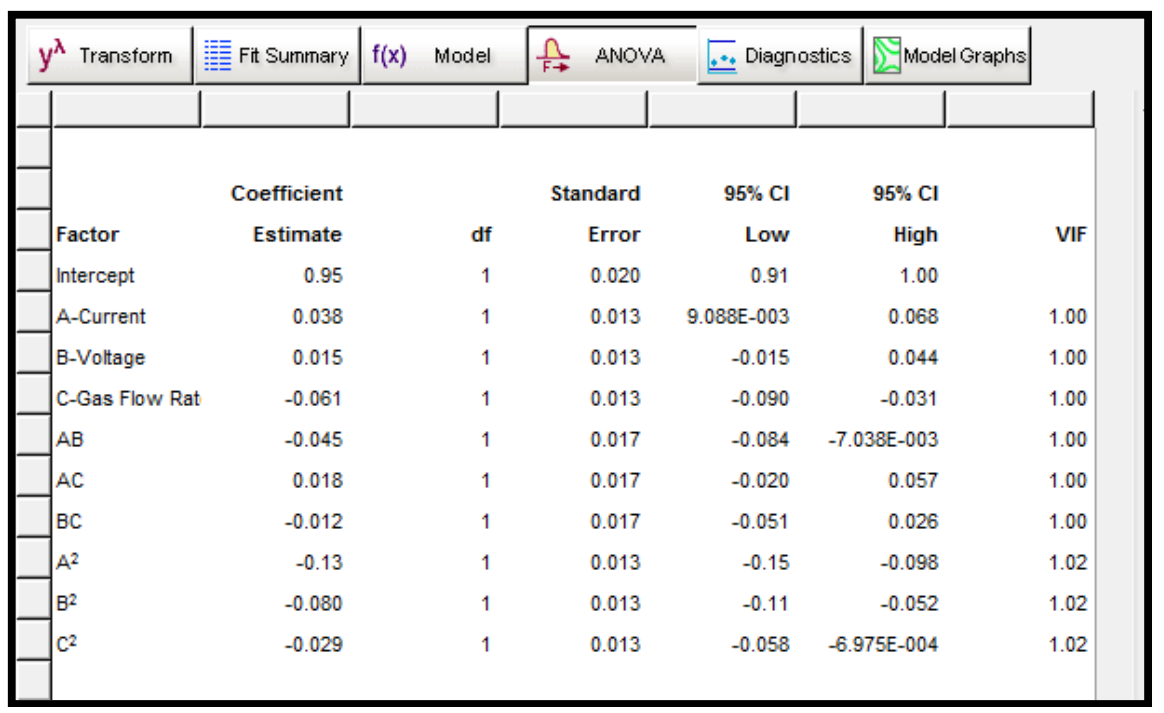

Figure 12. Coefficient estimates statistics for minimizing the aspect ratio.

terms, 1.02 for the quadratic terms as observed in Figure 12 indicate a significant model in which the variables are highly correlated with the responses.

The optimal equation which shows the individual effects and combine interactions of the selected input variables (Current, Voltage and Gas flow rate) against the mesured responses (Aspect ratio), is presented the actual factors as shown in Figure 13.

The diagnostics case statistics which shows the observed values of each respones variable (Aspect ratio) against their predicted values is presented in Figure 14. The diagnostic case statistics actually give insight into the model strength and the adequacy of the optimal second order polynomial equation.

Lower residual values resulting to lower leverages as observed in Tables are indicators of a well fitted model. To asses the accuracy of prediction and established the suitability of response surface methodology using the quadratic model, a reliability plot of the observed and predicted values of aspect ratio is presented in Figure 15.

To accept any model, its satisfactoriness must be checked by an appropriate statistical analysis. To diagnose the statistical properties of the model, the normal probability plot of residual of aspect ratio is presented in Figure 16.

To study the effects of combine variables on each response (Aspect ratio, 3D surface plots presented in Figure 17.

The 3D surface plot as observed in Figure 17 shows the relationship between the input variables (current, voltage and gas flow rate) and the response variables (Aspect ratio) to the work piece. It is a 3-dimensional surface plot which was employed to give a clearer concept of the response surface. As the colour of the curved surface gets darker, the aspect ratio decreases.

Finally, numerical optimization was performed to ascertain the desirability of the overall model. In the numerical optimization phase, we ask Design Expert to minimize the aspect ratio, also determining the optimum value of current, 


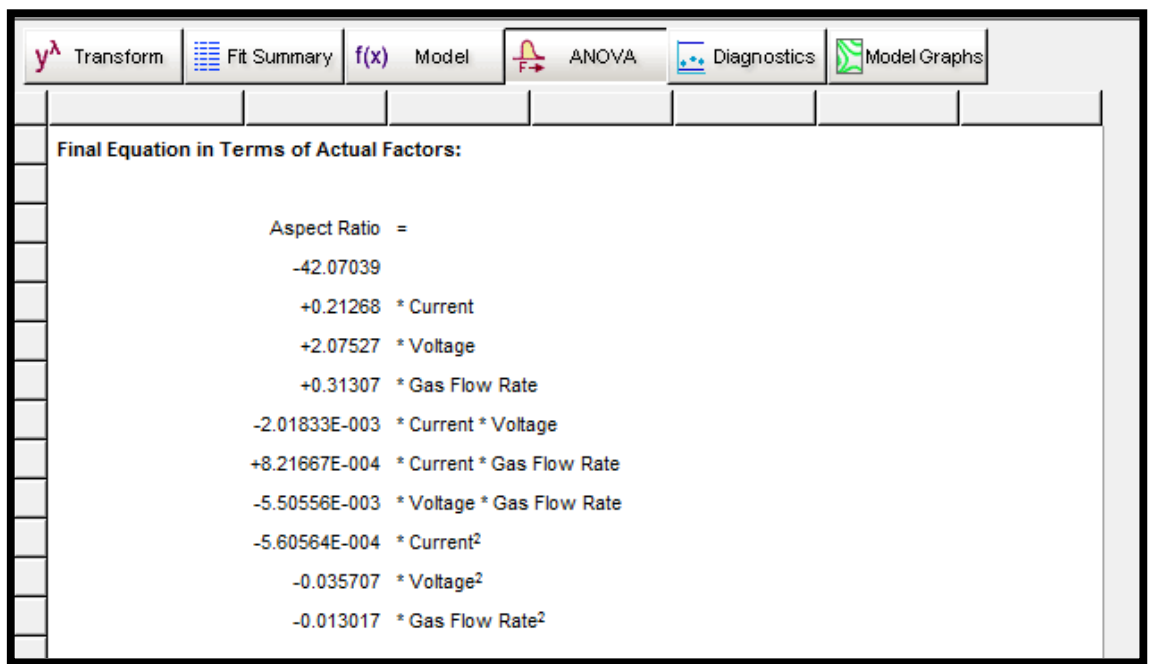

Figure 13. Optimal equation in terms of actual factors for minimizing the aspect ratio.

\begin{tabular}{|c|c|c|c|c|c|c|c|c|c|}
\hline \multirow[t]{2}{*}{$\mathrm{y}^{\lambda}$ Transform } & Fit Summary & $f(x) \quad$ Model & $\frac{\Omega}{F \rightarrow}$ ANOVA & \multicolumn{3}{|c|}{ WModel Graphs } & & & \multirow[b]{2}{*}{ 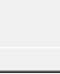 } \\
\hline & & & & & & & & & \\
\hline Response & 1 & Aspect Ratio & Transform: & None & & & & & \\
\hline \multicolumn{10}{|c|}{ Diagnostics Case Statistics } \\
\hline & & & & & Internally & Externally & Influence on & & \\
\hline Standard & Actual & Predicted & & & Studentized & Studentized & Fitted Value & Cook's & Run \\
\hline Order & Value & Value & Residual & Leverage & Residual & Residual & DFFITS & Distance & Order \\
\hline 1 & 0.71 & 0.68 & 0.025 & 0.670 & 0.902 & 0.893 & 1.271 & 0.165 & 13 \\
\hline 2 & 0.85 & 0.81 & 0.034 & 0.670 & 1.214 & 1.247 & 1.776 & 0.299 & 14 \\
\hline 3 & 0.81 & 0.83 & -0.014 & 0.670 & -0.508 & -0.488 & -0.695 & 0.052 & 15 \\
\hline 4 & 0.72 & 0.78 & -0.058 & 0.670 & -2.059 & -2.573 & $=-3.66$ & 0.860 & 16 \\
\hline 5 & 0.60 & 0.55 & 0.052 & 0.670 & 1.847 & 2.158 & $=3.07$ & 0.692 & 17 \\
\hline 6 & 0.76 & 0.76 & $8.278 \mathrm{E}-003$ & 0.670 & 0.296 & 0.282 & 0.401 & 0.018 & 18 \\
\hline 7 & 0.61 & 0.65 & -0.040 & 0.670 & -1.426 & -1.516 & $=-2.16$ & 0.412 & 19 \\
\hline 8 & 0.64 & 0.67 & -0.031 & 0.670 & -1.114 & -1.129 & -1.608 & 0.252 & 20 \\
\hline 9 & 0.51 & 0.53 & -0.016 & 0.607 & -0.538 & -0.518 & -0.644 & 0.045 & 7 \\
\hline 10 & 0.68 & 0.66 & 0.025 & 0.607 & 0.813 & 0.798 & 0.993 & 0.102 & 8 \\
\hline 11 & 0.63 & 0.70 & -0.074 & 0.607 & -2.416 & -3.551 & $=-4.42$ & 0.902 & 9 \\
\hline 12 & 0.83 & 0.75 & 0.082 & 0.607 & 2.691 & 4.860 & $=6.04$ & $=1.12$ & 10 \\
\hline 13 & 0.98 & 0.97 & 4.644E-003 & 0.607 & 0.152 & 0.144 & 0.180 & 0.004 & 11 \\
\hline 14 & 0.77 & 0.77 & $3.757 \mathrm{E}-003$ & 0.607 & 0.123 & 0.117 & 0.145 & 0.002 & 12 \\
\hline 15 & 0.95 & 0.95 & $-3.402 E-004$ & 0.166 & -0.008 & -0.007 & -0.003 & 0.000 & 1 \\
\hline 16 & 0.95 & 0.95 & $-1.402 E-004$ & 0.166 & -0.003 & -0.003 & -0.001 & 0.000 & 2 \\
\hline 17 & 0.95 & 0.95 & $-2.402 E-004$ & 0.166 & -0.005 & -0.005 & -0.002 & 0.000 & 3 \\
\hline 18 & 0.95 & 0.95 & $-3.402 E-004$ & 0.166 & -0.008 & -0.007 & -0.003 & 0.000 & 4 \\
\hline 19 & 0.95 & 0.95 & $-2.402 E-004$ & 0.166 & -0.005 & -0.005 & -0.002 & 0.000 & 5 \\
\hline 20 & 0.95 & 0.95 & $-1.402 E-004$ & 0.166 & -0.003 & -0.003 & -0.001 & 0.000 & 6 \\
\hline
\end{tabular}

Figure 14. Diagnostics case statistics report of observed and predicted aspect ratio.

voltage and gas flow rate. The interphase of the numerical optimization is presented as shown in Figure 18.

The numerical optimization produces about twenty two (22) optimal solutions which are presented as shown in Figure 18.

From the results of Figure 19 it was observed that a current of $140.00 \mathrm{Amp}$, voltage of 25.00 volt and a gas flow rate of $15.00 \mathrm{~L} / \mathrm{min}$ will produce a weld material with aspect ratio of (0.646234). This solution was selected by Design Expert as the optimal solution with a desirability value of $96.70 \%$.

It can be deduce from the result that the model developed based on response surface methodology and optimized using numerical optimization method, 


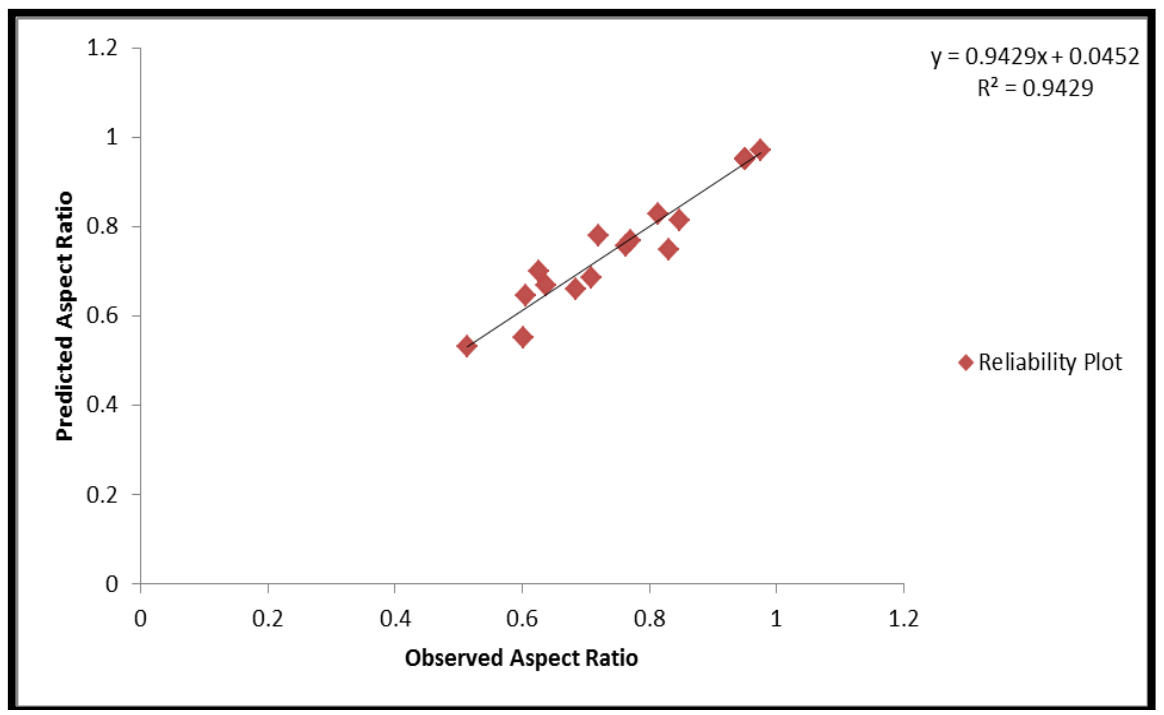

Figure 15. Reliability plot of observed versus predicted aspect ratio.

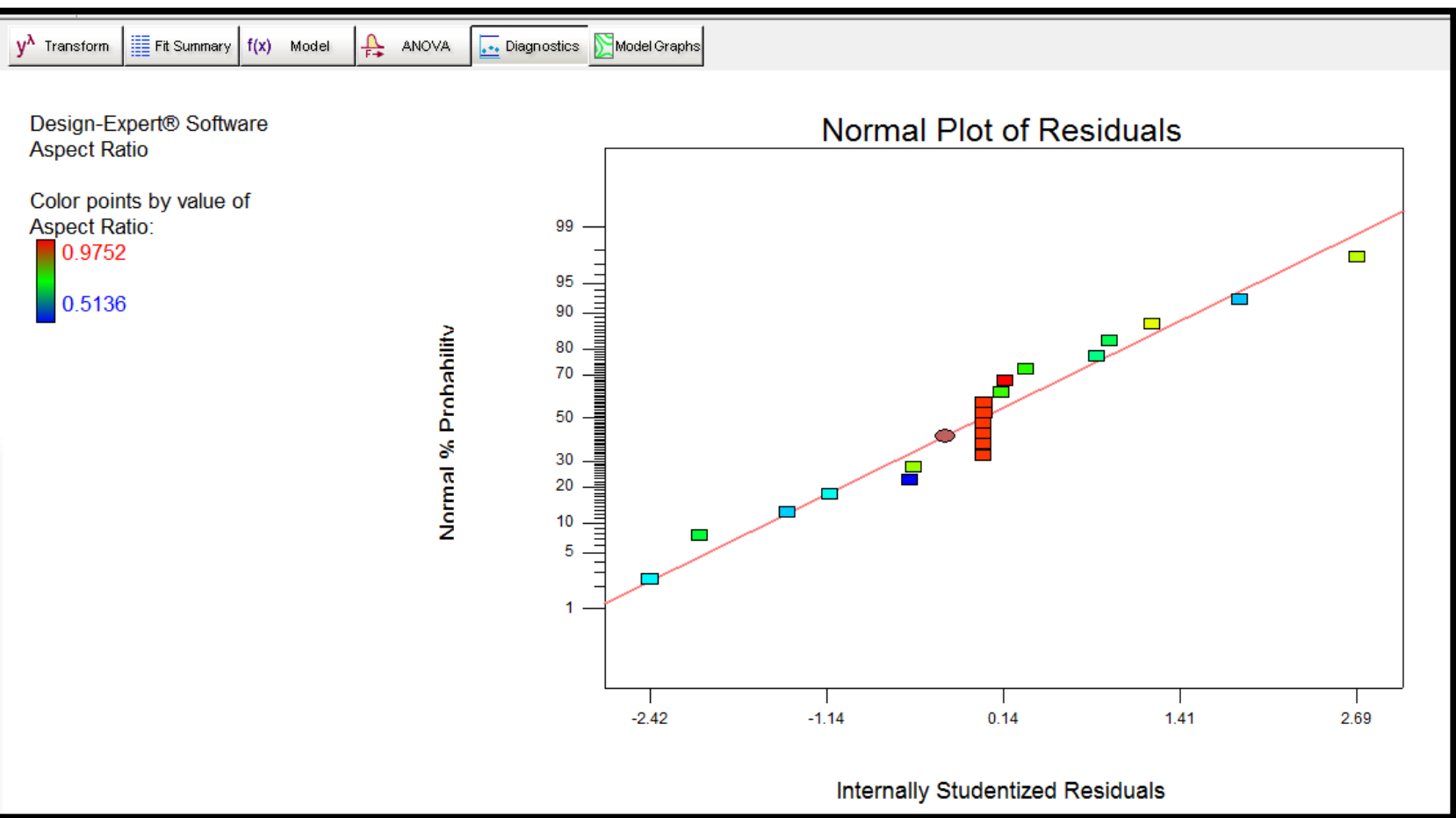

Figure 16. Normal probability plot of studentized residuals for minimizing aspect ratio.

Aspect ratio with an accuracy of $96.67 \%$.

One of the uniqueness of Response Surface Methodology (RSM) is its ability to carry out predictions based on the numerical optimal solution or models it developed. RSM displays this strenght by generation of contur plots which shows the response varaible of interest and the coresponding input factors. Hence, based on the optimal solution, the contour plots showing aspect ratio response variable against the optimized value of the input variable is presented in Figure 20. 


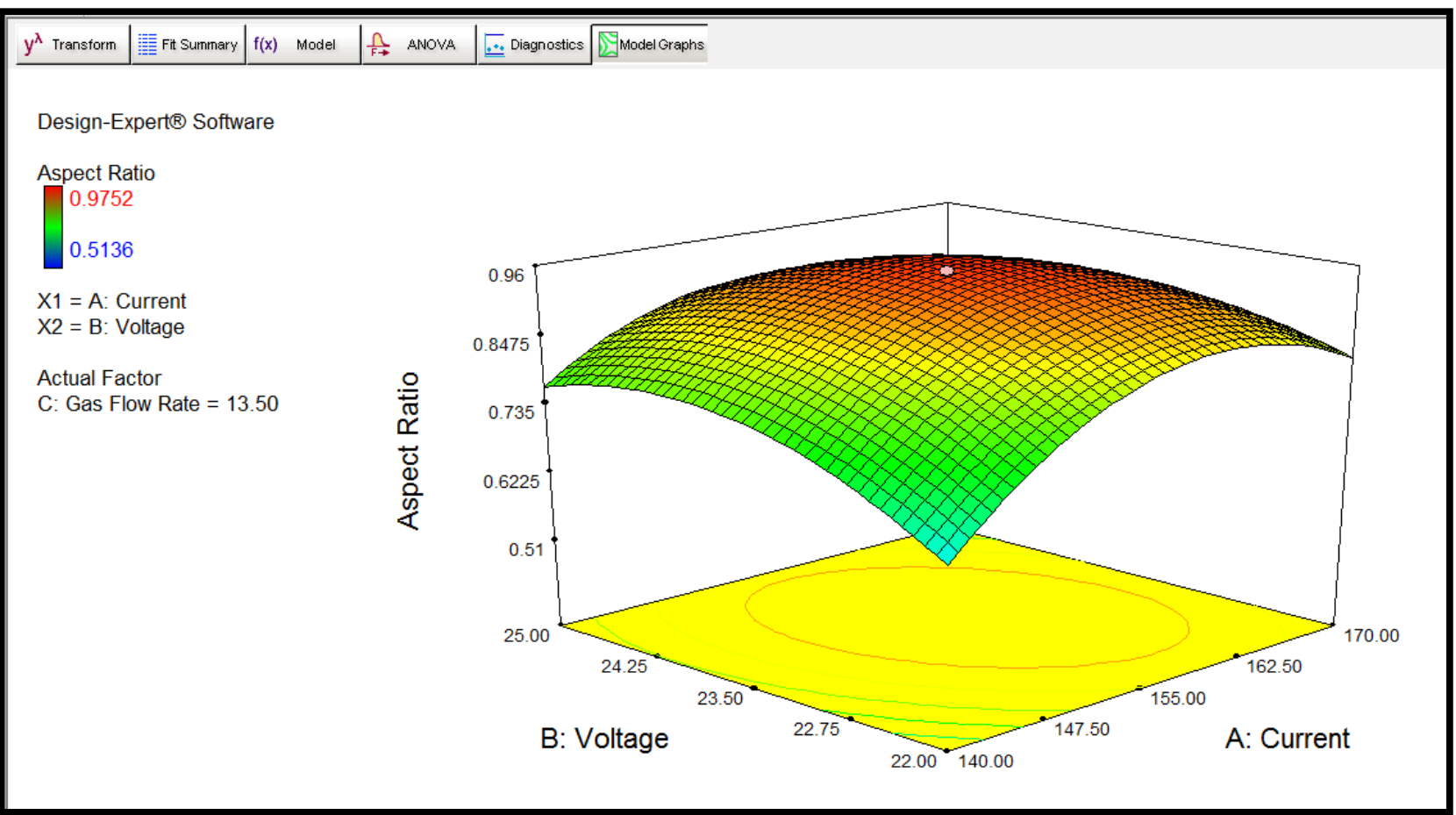

Figure 17. Effect of Current and Voltage on Aspect Ratio Ransfer.

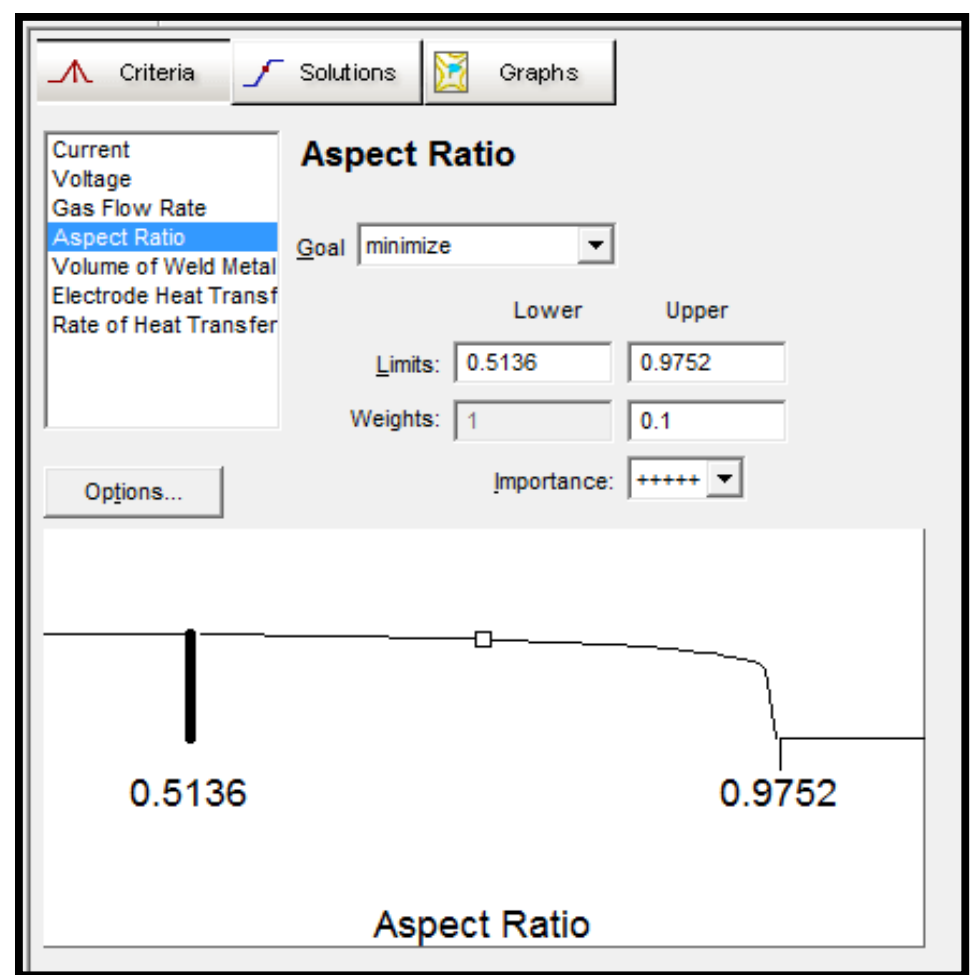

Figure 18. Interphase of numerical optimization model for minimizing the aspect ratio.

\subsection{Discussion}

In this study, the response surface methodology was used to optimize the aspect 


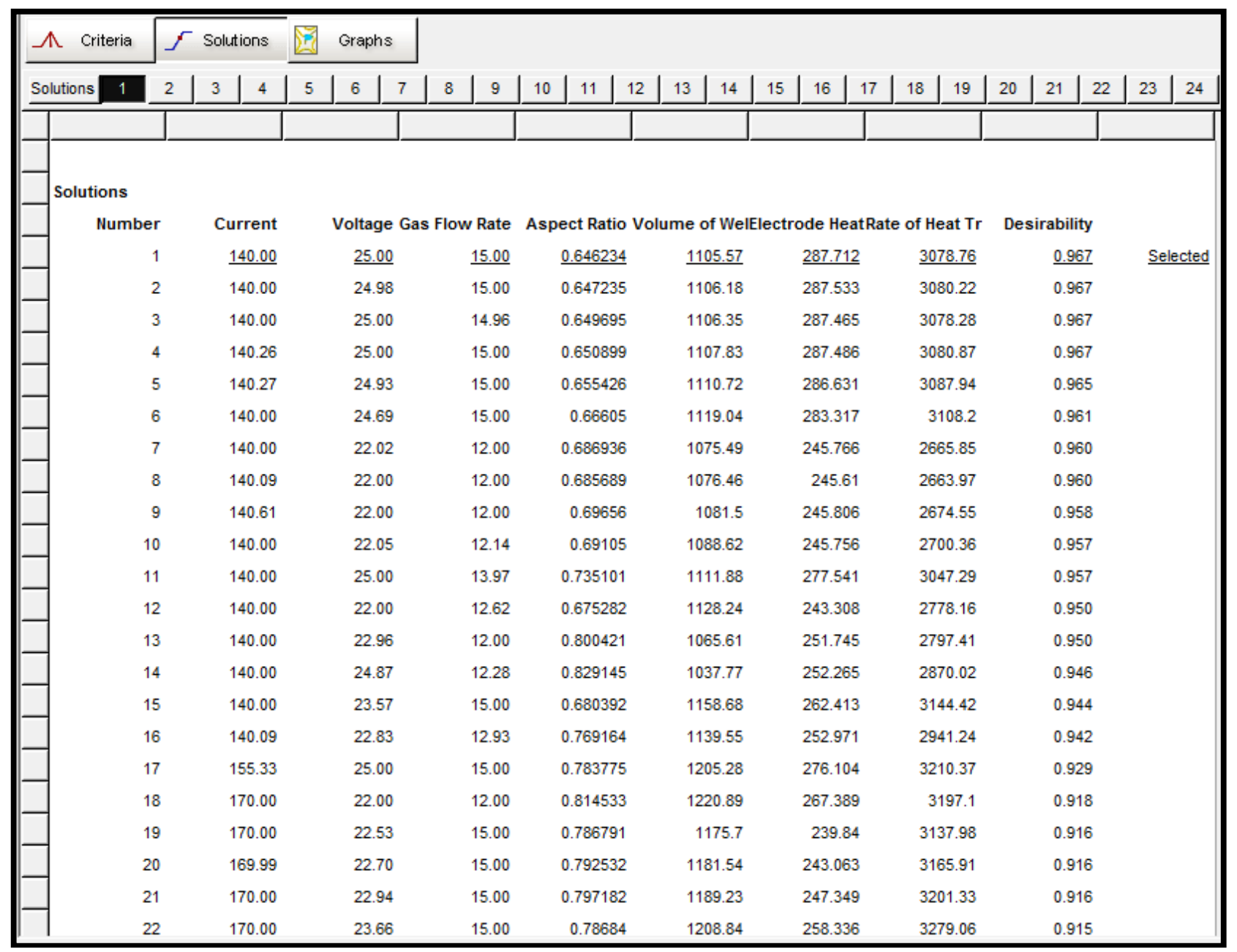

Figure 19. Optimal solutions of numerical optimization.

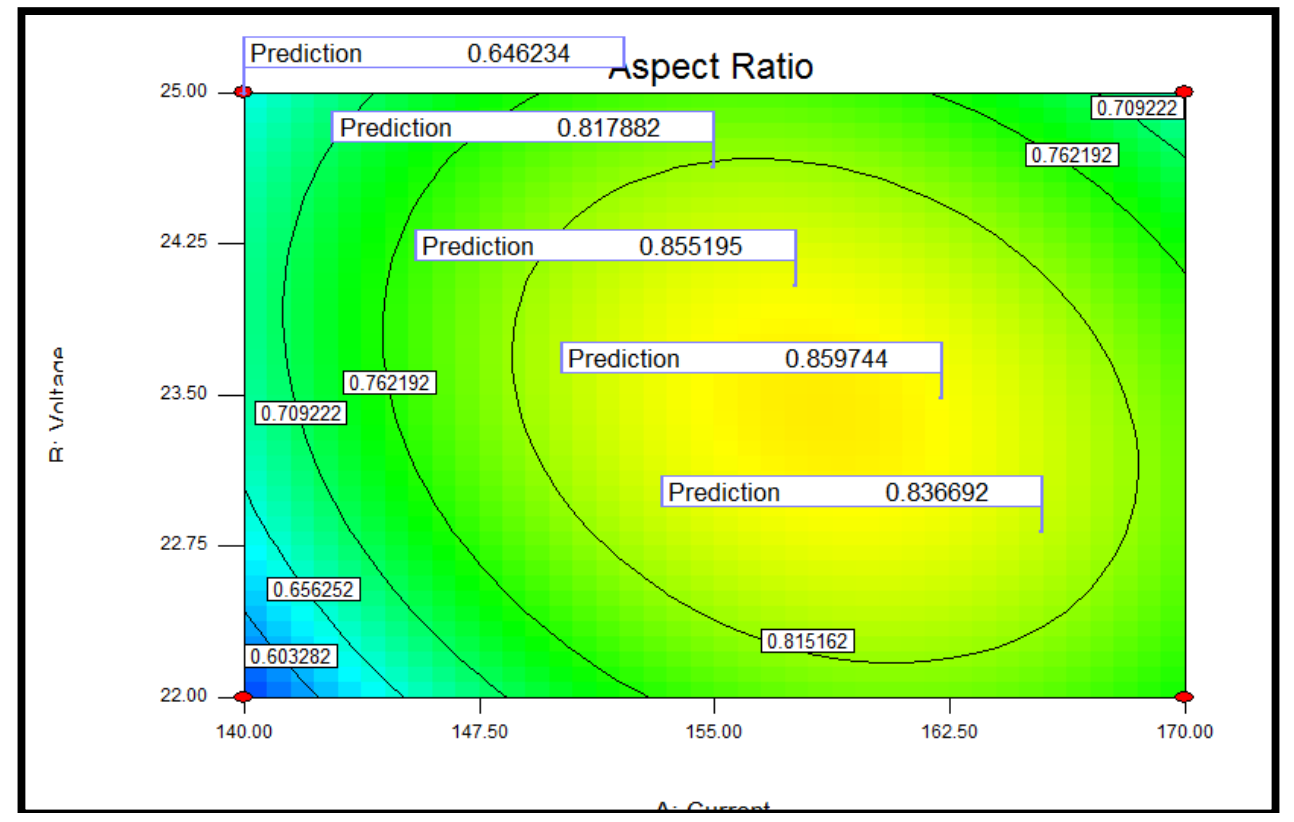

Figure 20. Predicting the Aspect ratio using contour plot. 
ratio of tungsten inert gas mild steel welds. A model was developed using RSM. Result of Figure 7 revealed that the model is of the quadratic type which requires the polynomial analysis order as depicted by a typical response surface design. Analysis of the model standard error was employed to assess the suitability of response surface methodology using the quadratic model to optimize the selected responses to a desired range. From the results of Figure 8, it was observed that the model have a low standard error ranging from 0.27 for the individual terms, 0.35 for the combine effects and 0.26 for the quadratic terms. Standard errors should be similar within type of coefficient; the smaller the standard error the better the model. The error values were also observed to be less than the model basic standard deviation of 1.0 which suggests that response surface methodology was ideal for the optimization process. The correlation matrix of regression coefficient is presented in Figure 9. A lower value of the off diagonal indicates a well fitted model that is strong enough to navigate the design space and adequately optimize the selected response variables. In assessing the strength of the quadratic model, one way analysis of variance (ANOVA) was done for each response variable and result is presented in Figure 10. To validate the adequacy of the model based on its ability to optimize the weld aspectratio, the goodness of fit statistics presented in Figure 11 was adopted. Coefficient of determination (R2) values of 0.9427 as observed in Figure 11 for aspect ratio, which indicated the adequacy of the models. Adequate precision values of 12.79 as observed for aspect ratioin Figure 11 indicated adequacy of the strength of the signal. The diagnostic case statistics actually give insight into the model strength and the adequacy of the optimal second order polynomial equation. To assess the accuracy of the prediction and established the suitability of response surface methodology using the quadratic model, a reliability plot of the observed and predicted values of each response was obtained as presented in Figure 15.

The 3D surface plot as observed in Figure 17 shows the relationship between the input variables (voltage, current and gas flow rate) and the response variables (aspect ratio). It is a 3 dimensional surface plot which was employed to give a clearer concept of the response surface in terms of the strength of the interactions between the input variables and the respective selected responses. Similarly, based on the optimal solution the expert system generated contour plots as observed in Figure 20 showing several predicted responses and their respective input variables, all within the boundaries of experimental design.

Finally, numerical optimization was performed to ascertain the desirability of the overall model. In the numerical optimization phase, Design Expert was asked to minimize the aspect ratio, while also determining the optimum value of voltage, current and gas flow rate.

\section{Conclusion}

The aspect ratio is a very important factor considered in assessing the quality of welds. The models developed possess a variance inflation factor of 1.0 and P- 
values $<0.05$ indicating that the model is significant; the model also possessed a high goodness of fit with $\mathrm{R}^{2}$ (Coefficient of determination) values of $94 \%$ for aspect ratio. Adeq Precision measures the signal to noise ratio; a ratio greater than 4.0 is desirable. Adequate precision values of 12.79 were observed for the Aspect ratio. The model produced numerical optimal solution of Current 140.0 Amp, Voltage of 25 Volt and a Gas flow rate of $15 \mathrm{~L} / \mathrm{min}$ will produce a welded material having aspect ratio of 0.646234 at a desirability value of $96.7 \%$. Therefore, the aspect ratio was minimized, optimized within a controlled range. In this research, the following has been established. An approach using the Response Surface Methodology to determine the optimum aspect ratio which translates into better weld quality has been successfully demonstrated. It has been shown that the optimization and prediction of aspect ratio have a significant effect on the quality and integrity of welded joints. It is, therefore, recommended that welding and fabrication industries should endeavor to use the optimum welding process parameters achieved in this study to produce high quality welds in Tungsten inert gas welding process.

\section{Conflicts of Interest}

The authors declare no conflicts of interest regarding the publication of this paper.

\section{References}

[1] Etin-Osa, C.E. and Achebo, J.I. (2017) Analysis of Optimum Butt Welded Joint for Mild Steel Components Using FEM (ANSYS). American Journal of Naval Architecture and Marine Engineering, 2, 100-109. https://doi.org/10.11648/j.aas.20170206.12

[2] Achebo, J.I. and Etin-Osa, C.E. (2017) Optimization of Weld Quality Properties Using Analytical Hierarchy Process (AHP). Journal of Nigerian Association of Mathematical Physics, 39, 389-396.

[3] Kelkar, G.P. (2018) http://www.welding-consultant.com/WeldCracks.pdf

[4] Achebo, J.I., Mokogwu, C.N. and Etin-osa, C.E. (2017) Optimization of Gmaw Process Parameters from Clustered Bead Geometry Based on the Fuzzy C-Means Algorithm. Journal of Nigerian Association of Mathematical Physics, 39, 397-408.

[5] Schneider, C.F., Lisboa, C.P., Silva, R.A. and Lermen, R.T. (2017) Optimizing the Parameters of TIG-MIG/MAG Hybrid Welding on the Geometry of Bead Welding Using the Taguchi Method. Journal of Manufacturing and Material Processing, 1, 14. https://doi.org/10.3390/jmmp1020014

[6] Magudeeswaran, G., Nair, S.R., Sundar, L. and Harikannan, N. (2014) Optimization of Process Parameters of the Activated Tungsten Inert Gas Welding for Aspect Ratio of UNS S32205 Duplex Stainless Steel Welds. Defence Technology, 10, 251-260. https://doi.org/10.1016/j.dt.2014.06.006

[7] Kolahan, F. and Heidari, M. (2009) A New Approach for Predicting and Optimizing Weld Bead Geometry in GMAW. World Academy of Science, Engineering and Technology International Journal of Mechanical, Aerospace, Industrial, Mechatronic and Manufacturing Engineering, 3, 1391-1394.

[8] Vignesh, S., Babu, P.D., Muthukumaran, G., Vinoth, S.M. and Sureshbabu, K. 
(2016) Development of Mathematical Models and Optimization of the Laser Welding Process Parameters Using Response Surface Methodology. ARPN Journal of Engineering and Applied Sciences, 11, 7979-7983.

[9] Prajapati, D.R. and Cheema, D.V.S. (2013) Optimization of Weld Crack Expansion Defect of Wheel Rims by Using Taguchi Approach: A Case Study. International Journal of Innovative Research in Science, Engineering and Technology, 2, 34373446.

[10] Gunaraj, V. and Murugan, N. (1999) Application of Response Surface Methodology for Predicting Weld Bead Quality in Submerged Arc Welding of Pipes. Journal of Materials Processing Technology, 88, 266-275.

https://doi.org/10.1016/S0924-0136(98)00405-1 